\title{
A COMPARATIVE STUDY OF EPIDURAL NALBUPHINE WITH BUPIVACAINE VS. BUPIVACAINE ALONE IN INFRAUMBILICAL SURGERIES
}

\author{
Chithra Devi Ramakrishnan1, Rani Vasantha Kumari Shunmugavelu ${ }^{2}$
}

${ }_{1}^{1}$ Assistant Professor, Department of Anaesthesia, Government Theni Medical College, Theni. ${ }^{2}$ Assistant Professor, Department of Anaesthesia, Government Theni Medical College, Theni.

\section{ABSTRACT}

\section{BACKGROUND}

Analgesia, one of the components of triad of anaesthesia, has now extended to relief of postoperative pain, chronic pain and cancer pain. The spinal route of analgesia plays an important role in the intra and postoperative period. Effective postoperative analgesia reduces postoperative morbidity, allows early ambulation and discharge.

\section{MATERIALS AND METHODS}

This study was done in 100 patients who belonged to ASA grade I \& II with age of 20-60 years and underwent elective infraumbilical surgeries. After thorough aseptic precaution, L1-L2 or L2-L3 space located and using a 16 gauge Huber point Tuohy needle, epidural space was identified with loss of resistance technique. Through the epidural catheter, a test dose of $2 \mathrm{~mL}$ of $1 \%$ lignocaine with 10 micrograms of adrenaline was injected and finally the total dose of $15 \mathrm{~mL}$ of $0.5 \%$ bupivacaine with injection nalbuphine was injected through the catheter and the patients were positioned for the surgery. The pulse rate, blood pressure, respiratory rate were monitored every 5 minutes. Continuous oxygen saturation monitoring was done. At the end of surgery, patients were observed in the recovery room and in the postoperative ward. The level of consciousness assessed ever $1 / 2$ hour and graded according to the sedation score. Patients were asked to mark a point scale on the 10-point visual analogue scale of pain according to the intensity of pain. The observation was done every 30 minutes. The pain relief is graded according to VAPS.

\section{OBSERVATION AND RESULTS}

Patients in both groups were comparable in age, duration, the site and type of surgery and baseline parameters at the starting of procedure. There were statistically no significant differences between mean age distribution, surgery performed, duration of procedure and baseline parameters in both groups. In this study, rapid onset in group A patients is due to synergistic effect of nalbuphine and bupivacaine. In case of time of onset of motor block, the actual difference between the mean is $5.04-$ the study is significant $(\mathrm{P}<0.000)$. In the group $\mathrm{A}$, the regression time was the range of $60-83$ minutes with the minimum VAPS was 1 and maximum 3. Hence, the quality of analgesia was fair in $30(85.7 \%)$ patients and good in $5(14.3 \%)$. In the group B, the regression time was the range of 54-84 minutes and the quality of analgesia was not assessed since all of them received postoperative narcotic supplementation after the surgery. Hence, the mean duration of surgery was 61.48 minutes, and 63 minutes in Group B. In Group A, patients had sedation score with mean of 0.46 ( $p$ value 0.000 ) which is statically significant. In Group B, all patients were awake. There is significance in BP maintenance in group A, whereas in group B it falls below the baseline value after 5 minutes and 15 minutes and then raises after $30 \mathrm{~min}$. and 45 minutes. No hypotension occurred in group A and in group B.

\section{CONCLUSION}

In our study, the epidural nalbuphine hastens the onset of both sensory and motor blockade and significantly prolonged the duration of anaesthesia and postoperative analgesia, with stable haemodynamics.

\section{KEYWORDS}

Analgesia, Epidural, Postoperative.

HOW TO CITE THIS ARTICLE: Ramakrishnan CD, Shunmugavelu RVK. A Comparative study of epidural nalbuphine with bupivacaine vs. bupivacaine alone in infraumbilical surgeries. J. Evolution Med. Dent. Sci. 2016;5(77):5710-5715, DOI: $10.14260 /$ jemds/2016/1288

\section{BACKGROUND}

The relief of pain during surgery is the raison d'etre of anaesthesia. The international association for the study of pain has defined "pain is an unpleasant sensory and emotional experience associated with actual or potential tissue damage". Pain is always underestimated and undertreated.

Financial or Other, Competing Interest: None.

Submission 01-08-2016, Peer Review 12-09-2016,

Acceptance 19-09-2016, Published 24-09-2016.

Corresponding Author:

Dr. Chithra Devi Ramakrishnan,

\#21-1-54, A2G, Court Road, Usilampatti,

Madurai District, Tamilnadu.

E-mail:drrcdevi@gmail.com

DOI: $10.14260 /$ jemds $/ 2016 / 1288$
Analgesia, one of the components of triad of anaesthesia has now extended to relief of postoperative pain, chronic pain and cancer pain. It is achieved by use of drugs administered through different routes and techniques among which the spinal route of analgesia plays an important role in the intra and postoperative period $1,2,3$. Effective postoperative analgesia reduces postoperative morbidity, allows early ambulation and discharge.

The spinal cord has taken the centre stage in analgesia practice following the demonstration of analgesia with intrathecal morphine 4 by Yaksh and Rudy (1977). Deposition of drugs in the epidural and subarachnoid space paved a new era for pain relief. In our study, we compare the effects of epidural Nalbuphine and $0.5 \%$ Bupivacaine with that of $0.5 \%$ Bupivacaine alone in infraumbilical surgeries with respect to 
the onset of sensory blockade, the onset of motor blockade, postoperative analgesia and the quality of analgesia.

\section{MATERIALS AND METHODS}

This study was done in 100 patients who belonged to ASA grade I \& II with age of 20-60 years and underwent elective infraumbilical surgeries were chosen.

\section{Exclusion Criteria}

- Patients with spinal deformities.

- Local skin sepsis.

- Bleeding disorders.

- Psychiatric illness.

Informed consent obtained after explaining the procedure. Preanaesthetic assessment done to find out systemic illness complicating anaesthesia.

\section{Premedication}

Inj. Atropine $0.02 \mathrm{mg} / \mathrm{kg}$ given 45 minutes prior to surgery. No narcotic premedication. The patients were explained about the 10 -point visual analogue of pain scale. The patients were randomly chosen into two groups.

\section{Group A}

Received $15 \mathrm{~mL}$ of $0.5 \%$ bupivacaine with nalbuphine $10 \mathrm{mg}$.

\section{Group B}

Received $15 \mathrm{~mL}$ of $0.5 \%$ bupivacaine alone.

\section{TECHNIQUE}

An intravenous line with dextrose normal saline started. Baseline recording of pulse rate, blood pressure, respiratory rate and oxygen saturation noted down. Patients were placed in the right lateral position on a horizontal table with head supported by a pillow.

After thorough aseptic precaution, L1-L2 or L2-L3 space located and using a 16 gauge Huber point Tuohy needle epidural space was identified with loss of resistance technique. Epidural catheter was inserted and fixed.

Aspiration was done to rule out subarachnoid or intravascular placement of the catheter. A test dose of $2 \mathrm{~mL}$ of $1 \%$ lignocaine with 10 micrograms of adrenaline was injected through the catheter and finally the total dose of $15 \mathrm{~mL}$ of $0.5 \%$ bupivacaine with injection nalbuphine was injected through the catheter and the patients were positioned for the surgery.

The level of sensory blockade was assessed every 2 minutes. The time taken for level of block at T10 and the maximum time for maximum level of block noted down. The time taken for grade 3 motor block noted down. Surgeons were asked to proceed with the surgery only after the maximum level of blockade was established. The 2 segment regression time was noted. The pulse rate, blood pressure, respiratory rate were monitored every 5 minutes. Continuous oxygen saturation monitoring done. A fall in systolic blood pressure by $20 \%$ from the baseline value was considered as hypotension and managed with IV fluids, oxygen and inj. Ephedrine in incremental doses. At end of surgery, patients were observed in the recovery room for further two hours and sent to postoperative ward. The level of consciousness assessed ever $1 / 2$ hour and graded according to the sedation score.
Patients were asked to mark a point scale on the 10-point visual analogue scale of pain according to the intensity of pain. The observation was done every 30 minutes. The pain relief is graded according to VAPS as follows.

$\begin{array}{ll}\text { VAPS } & \text { Quality of Analgesia } \\ 0-1 & \text { Excellent } \\ 1-4 & \text { Fair } \\ 4-6 & \text { Good } \\ 6-8 & \text { Slight } \\ 8-10 & \text { No relief }\end{array}$

\section{Duration of Analgesia}

The duration of analgesia was taken as the period from the time of giving epidural analgesia till the patient's first requirement of systemic analgesic medication. Supplementary analgesia was given when VAPS was more than 6 .

\section{Sedation Score Level}

The level of sedation assessed every 30 minutes and graded according to the sedation score (Brain and Ready).

0 - Fully awake.

1 - Normal sleep.

2 - Drowsy, arousable on touch.

3 - Drowsy, arousable to painful stimuli.

4 - Somnolent.

The side effects due to Nalbuphine like nausea, vomiting, pruritis, urinary retention were noted down. Comparison between group $A$ and group $B$ were done using students ' $t$ ' test and the level of significance was taken below 0.05 .

\section{OBSERVATION AND RESULTS}

Patients in both groups were comparable in age, duration, the site and type of surgery and baseline parameters at the starting of procedure. (Table 1, 2 \&3). The observations recorded in this study are given as follows.

Results of Study Characters and Baseline Measurement

Age: Group A: The mean of 43.26 .

Group B: The mean of 43.20

' $t$ ' test ( $p$ value) 0.974

Age Distribution: $t$ test is 0.792

Surgery Performed: 0.766 (chi-square)

\section{Duration of Procedure}

\begin{tabular}{|c|c|c|c|}
\hline Group & A & B & t \\
\hline & 61.4 & 63 & 0.273 \\
\hline Systolic BP & 118.12 & 121.32 & 0.276 \\
\hline Pulse Rate & 80.56 & 80.34 & 0.858 \\
\hline \multicolumn{4}{|c|}{$>0.05$ insignificant } \\
\hline
\end{tabular}

$\mathrm{t}$ (table value $)=0.05$

There was statistically no significant difference between mean age distributions, surgery performed duration of procedure and baseline parameters in both groups.

\section{Results of Variables of Study Characters Between 2 Groups}

The significance between the study and control groups was tested using the standard error of difference between the means. 


\section{Time of Onset of Sensory Block (Table. 4)}

In group $\mathrm{A}$, the minimum time was 3 minutes and maximum 8 minutes with a mean time of 5.22. In group B, the minimum time was 6 minutes and maximum 12 minutes with a mean time of 9.52 minutes.

R. Fournier et al Oct 1998 studied and reported the administration of intrathecal nalbuphine resulting in a significantly faster onset related with the time to the lowest pain score $(18+11$ Vs. $66+75$ minutes, $\mathrm{P}<0.001)$.

In the study also rapid onset in group $A$ patients is due to synergistic effect of nalbuphine and bupivacaine.

\section{Time of Onset of Motor Block (Grade 3)}

All patients both groups developed Grade 3 motor block. The time latency for complete blockade was taken as the onset of motor block.

In group $\mathrm{A}$, the minimum time was 5 minutes and maximum 10 minutes with a mean time of 7.8.

In group $B$, the minimum time was 9 minutes and maximum 15 minutes with a mean time of 12.84 minutes.

Since actual difference between the mean is 5.04 - the study is significant $(\mathrm{P}<0.000)$.

\section{Segment Regression Time (Table 4)}

In the group $A$, the regression time was the range of $60-83$ minutes with mean of 70.14 .

In the group $\mathrm{B}$, the regression time was in the range of 5484 minutes with mean of 67 with $P<0.009$ which is significant.

\section{Quality of Analgesia}

The minimum VAPS was 1 and maximum 3 in Group A in the mean of 1.86

In group B, the quality of analgesia was not assessed since all of them received postoperative narcotic supplementation after the surgery.

In group A, the quality of analgesia was fair in 30 (85.7\%) patients and good in 5 (14.3\%).

Supported by the study of Donadoni R et al 1988 in which concluded that nalbuphine was far superior in onset duration and quality of pain relief in orthopaedic surgeries when compared to pethidine.

\section{Duration of Surgery}

In Group A, the mean duration of surgery was 61.48 minutes, and 63 minutes in Group B; t value is 0.27.

\section{Sedation}

In Group A, 23 patients had sleep resembling natural sleep with sedation score of 1 and 27 patients with sedation score of 2 with the mean of 0.46 ( $p$ value 0.000 ) which is statically significant.

In Group B, all patients were awake.

KC 1983 studied the role of epidural analgesic and sedatives in the management of pain and agitation in which he compared nalbuphine with other narcotics.

\section{Respiratory Rate}

Respiratory rate $<10$ /minute was not noted in any of the patients.

\section{Oxygen Saturation}

Measured by pulse oximetry was maintained above $95 \%$ in all patients.

Group A $\quad 98.8$.

Group B $\quad 97.2$

t test ( $p$ value is 0.000 ) which is significant.

\section{Changes Blood Pressure}

There is significance in BP maintenance in group A throughout the procedure as shown in table 5 , whereas in group B it falls below the base line value after 5 minutes and 15 minutes and then raises after 30 min and 45 minutes.

\section{Changes Pulse Rate}

No hypotension occurred in group A and in group B as shown in table 6. 11 patients had hypotension. In contrast to pentazocine and butorphanol, nalbuphine does not increase systolic blood pressure and pulmonary arterial pressure, heart rate (or) atrial filling pressure (Lee et al; 1976).

\section{Side Effects}

Nausea And Vomiting occurred in 1 patient in group B.

Urinary Retention could not be studied as the patients were catheterised at the end of surgery.

Parker et al studied the interaction between nalbuphine and hydromorphone and concluded that the combination of hydromorphone $0.075 \mathrm{mg} / \mathrm{mL}$ and nalbuphine $0.04 \mathrm{mg} / \mathrm{mL}$ resulted in lower nausea score and decreased incidence of urinary retention compared with hydromorphone alone.

Pruritis: No patient had pruritis in the postoperative period in group A and in group B.

Drowsiness: In group A, no patients had sedation score of more than one. In group 'B', all the patients were awake.

Respiratory Depression: Did not occur in any of the patients. Nalbuphine 10 to $20 \mathrm{mg}$ reverses postoperative ventilation caused by fentanyl but maintains analgesia (Bailey et al 1987; Molden Hawer et al 1985).

Depression of ventilation is similar to that of morphine until $30 \mathrm{mg}$ of nalbuphine is exceeded, after which no further depression of ventilation occurs (ceiling effect) (Gal et al; 1982).

\begin{tabular}{|c|c|c|c|c|c|c|}
\hline \multicolumn{2}{|c|}{$\begin{array}{c}\text { Study } \\
\text { Groups }\end{array}$} & N & Mean & S.D & S.E & $\begin{array}{c}\text { T- Test } \\
\text { (p Value) }\end{array}$ \\
\hline \multirow{2}{*}{$\begin{array}{c}\text { Age of } \\
\text { the } \\
\text { patient }\end{array}$} & $\begin{array}{c}\text { Study } \\
\text { group } \\
\text { (Bupi+ } \\
\text { Nalbu) }\end{array}$ & 50 & 43.26 & 7.645 & 1.081 & \multirow{2}{*}{0.974} \\
\cline { 2 - 5 } & $\begin{array}{c}\text { Control } \\
\text { (Bupi) }\end{array}$ & 50 & 43.20 & 10.768 & 1.523 & \\
\hline \multicolumn{7}{|c|}{ Table 1: Age and Duration of the Procedure among } \\
the Study Groups
\end{tabular}




\begin{tabular}{|c|c|c|c|c|}
\hline \multicolumn{2}{|c|}{$\begin{array}{l}\text { Study } \\
\text { Groups }\end{array}$} & \multirow{2}{*}{$\begin{array}{c}\text { Frequency } \\
4\end{array}$} & \multirow{2}{*}{$\begin{array}{l}\% \\
8.0 \\
\end{array}$} & \begin{tabular}{|c|}
$\mathrm{X} 2$ \\
Test \\
(p \\
value)
\end{tabular} \\
\hline \multirow{5}{*}{$\begin{array}{l}\text { Study } \\
\text { group } \\
\text { (Bupi+ } \\
\text { Nalbu) }\end{array}$} & 20 - 30 yrs. & & & \multirow{11}{*}{0.792} \\
\hline & $30-40$ yrs. & 13 & 26.0 & \\
\hline & 40 - 50 yrs. & 25 & 50.0 & \\
\hline & 50 - 60 yrs. & 8 & 16.0 & \\
\hline & Total & 50 & 100.0 & \\
\hline \multirow{6}{*}{$\begin{array}{c}\text { Control } \\
\text { (Bupi) }\end{array}$} & 20 - 30 yrs. & 8 & 16.0 & \\
\hline & 30 - 40 yrs. & 12 & 24.0 & \\
\hline & 40 - 50 yrs. & 19 & 38.0 & \\
\hline & 50 - 60 yrs. & 10 & 20.0 & \\
\hline & $>60$ yrs. & 1 & 2.0 & \\
\hline & Total & 50 & 100.0 & \\
\hline
\end{tabular}

\begin{tabular}{|c|c|c|c|}
\hline $\begin{array}{c}\text { Study } \\
\text { Groups }\end{array}$ & & Frequency & $\%$ \\
\hline \multirow{7}{*}{$\begin{array}{l}\text { Study } \\
\text { group } \\
\text { (Bupi+ } \\
\text { Nalbu) }\end{array}$} & TVH & 5 & 10.0 \\
\hline & Herniotomy/rrhaphy & 18 & 36.0 \\
\hline & Varicose Veins & 13 & 26.0 \\
\hline & Appendicectomy & 11 & 22.0 \\
\hline & $\begin{array}{l}\text { Below-knee } \\
\text { amputation }\end{array}$ & 1 & 2.0 \\
\hline & SSG & 2 & 4.0 \\
\hline & Total & 50 & 100.0 \\
\hline \multirow{7}{*}{$\begin{array}{l}\text { Control } \\
\text { (Bupi) }\end{array}$} & TVH & 4 & 8.0 \\
\hline & Herniotomy/rrhaphy & 22 & 44.0 \\
\hline & Varicose Veins & 9 & 18.0 \\
\hline & Appendicectomy & 11 & 22.0 \\
\hline & $\begin{array}{l}\text { Below-knee } \\
\text { amputation }\end{array}$ & 3 & 6.0 \\
\hline & SSG & 1 & 2.0 \\
\hline & Total & 50 & 100.0 \\
\hline
\end{tabular}

Chi Square Test: $\mathrm{p}$ Value $=0.766$

\begin{tabular}{|c|c|c|c|c|c|c|}
\hline \multicolumn{2}{|c|}{ Study Groups } & $\mathbf{N}$ & Mean & S.D & S.E & $\begin{array}{c}\text { Independent T-Test } \\
\text { (p Value) }\end{array}$ \\
\hline \multirow{2}{*}{ Duration of procedure } & Study group (Bupi+ Nalbu) & 50 & 61.48 & 7.538 & 1.066 & \multirow{2}{*}{0.273} \\
\hline & Control (Bupi) & 50 & 63.00 & 6.171 & .873 & \\
\hline \multirow{2}{*}{ Baseline Systolic BP } & Study group (Bupi+ Nalbu) & 50 & 118.12 & 16.529 & 2.338 & \multirow{2}{*}{0.276} \\
\hline & Control (Bupi) & 50 & 121.32 & 12.353 & 1.747 & \\
\hline \multirow{2}{*}{ Baseline Pulse Rate (5 min.) } & Study group (Bupi+ Nalbu) & 50 & 80.56 & 6.276 & .888 & \multirow{2}{*}{0.858} \\
\hline & Control (Bupi) & 50 & 80.34 & 6.022 & .852 & \\
\hline \multicolumn{7}{|c|}{ Table 3: Group Statistics } \\
\hline
\end{tabular}

\begin{tabular}{|c|c|c|c|c|c|c|}
\hline & & $\mathbf{N}$ & Mean & S.D & S.E & $\begin{array}{c}\text { Independent T Test } \\
\text { (p Value) }\end{array}$ \\
\hline \multirow{2}{*}{ Time of onset of block } & Study group (Bupi+ Nalbu) & 50 & 5.22 & 1.234 & .174 & \multirow{2}{*}{0.000} \\
\hline & Control (Bupi) & 50 & 9.52 & 1.446 & .205 & \\
\hline \multirow{2}{*}{ Onset of Grade 3 motor block } & Study group (Bupi+ Nalbu) & 50 & 7.80 & 1.471 & .208 & \multirow{2}{*}{0.000} \\
\hline & Control (Bupi) & 50 & 12.84 & 1.390 & .197 & \\
\hline \multirow{2}{*}{ Two segment regression time } & Study group (Bupi+ Nalbu) & 50 & 70.14 & 6.138 & .868 & \multirow{2}{*}{0.009} \\
\hline & Control (Bupi) & 50 & 67.00 & 5.544 & .784 & \\
\hline Duration of Analgesia & Study group (Bupi+ Nalbu) & 50 & 287.40 & 29.054 & 4.109 & 0.000 \\
\hline \multicolumn{7}{|c|}{ Table 4: Variability of the Study Characters } \\
\hline
\end{tabular}

\begin{tabular}{|c|c|c|c|}
\hline Time in Minutes & Group A & Group B & t value \\
\hline 5 & 118.12 & 100.4 & 0.276 \\
\hline 15 & 114.84 & 100.4 & 0.000 \\
\hline 30 & 119.6 & 113.54 & 0.05 \\
\hline 45 & 112.72 & 120.86 & 0.000 \\
\hline \multicolumn{4}{|c|}{ Table 5: Shows the Changes in Blood Pressure } \\
\hline
\end{tabular}

\begin{tabular}{|c|c|c|c|}
\hline Time in Minutes & Group A & Group B & t value \\
\hline 5 & 80.6 & 80.3 & 0.8 \\
\hline 15 & 74 & 89 & 0.000 \\
\hline 30 & 72 & 92 & 0.000 \\
\hline 45 & 72 & 92 & 0.000 \\
\hline \multicolumn{2}{|c|}{ Table 6: Shows the Changes in Pulse Rate } \\
\hline
\end{tabular}

\section{DISCUSSION}

Epidural administration of narcotics for post-surgical analgesia is becoming increasingly popular with more practitioners. This is clearly because this modality of analgesia has unique advantages over conventional, intermittent IV/IM administration of narcotics 5,6 . Patients given epidural narcotics have fewer respiratory complications and can be mobilised sooner in the postoperative period.

However, the drug that has been utilised most widely, i.e., morphine, produces distressing side effect and sometimes potentially lethal complications like delayed and prolonged respiratory depression. Several other narcotics have been evaluated in order to identify a drug that affords as efficient analgesia but causes much less respiratory depression when given epidurally for epidural use. The agonist/antagonist narcotic agent ${ }^{7,8,9}$ can be expected to offer some scope in this respect, since the respiratory depression reaches ceiling level with higher receptor occupancy at higher dose of the drug. Apart from this, these drugs are not as potent as morphine in causing respiratory depression. In this study, neither bradypnoea nor frank respiratory depression was encountered.

The agonist-antagonist class of drugs have the advantage that they trend to release less histamine and thus cause less 
hypotension. Similarly, they also have less abuse potential. Thus, nalbuphine being an agonist-antagonist has all these advantages ${ }^{10,11,12}$.

Epidurally administered nalbuphine reported satisfactory outcome with regard to quality of analgesia and incidence of serious complications $13,14,15$. In the present study also there was no respiratory depression and nausea and vomiting; however, PaCO2 level were not monitored.

The quality of analgesia was good in patients given epidural nalbuphine16,17,18,19. At the end of any period of observation, more patients from group A had zero points on the VAS as compared to those from Group B. It was found that none of the Group B patients had zero pain score after $24 \mathrm{hrs}$. This could be because epidurally given nalbuphine could no longer provide pain relief after $24 \mathrm{hrs} .{ }^{20,21}$. while those in Group B could have demanded and obtained analgesia shortly before pain score was measured.

No troublesome side effects were encountered either in the experimental or in the control group. Some patients in Group A were very drowsy. After allowing them to sleep for half an hour, they were sufficiently awake to use the visual analogue scale. None required catheterisation of the urinary bladder. None experienced itching, vomiting, shivering, although other studies have reported these with extradural fentanyl, dimorphine and other opiates.

It was one of the explicit aims in the present study to measure the duration of analgesia in the epidural group, it was observed that patients demanded analgesia at the end of 7 hours (5.5 mean). In the study by Weksler et al, epidural nalbuphine provided a mean duration of analgesia for $8 \mathrm{hrs}$. and $45 \mathrm{~min}$. ( $\pm 2.25 \mathrm{hrs}$. $)$.

\section{SUMMARY}

In this study, epidural Nalbuphine was evaluated as an analgesic and its influence on BP, PR, oxygen saturation. Fifty adult patients undergoing infraumbilical surgery electively were included in the study. All were fit patients belonging to ASA category I/II. Fifty patients who were matched for age, type of surgery, duration of surgery and baseline parameters received analgesia according to the stranded protocol. They were control groups. Injection into epidural space in the study group was given before starting of surgery. Pain was measured on a visual analogue scale and PR, oxygen saturation by pulse oximetry.

When nalbuphine was given epidurally it provided excellent analgesia in the immediate intraoperative and postoperative period. As reported in several studies, nalbuphine offered good cardiovascular stability without the risk of several respiratory depression though it produced sedation in some of our patients. Our patients had good overall analgesia with improved respiratory function.

Nalbuphine when used with bupivacaine decreased the onset time of sensory blockade and time taken for grade 3 motor block. It produces postoperative analgesia for period of 4-7 hours with a mean duration of 5.5 hours.

No incidence of nausea, vomiting, shivering were noted with epidural nalbuphine ${ }^{22,23}$.

Nalbuphine when combined with bupivacaine hastens the onset of sensory block. It is speculated that with studies invoking larger sample of patients, nalbuphine may well emerge as an alternative to other opioids for epidural use.

\section{CONCLUSION}

This prospective, randomised, single blind study, wherein Nalbuphine in a dose of $10 \mathrm{mg}$ was added epidurally to $0.5 \%$ Bupivacaine for infraumbilical surgeries concludes that "epidural Nalbuphine hastens the onset of both sensory and motor blockade and significantly prolonged the duration of anaesthesia and postoperative analgesia, with stable haemodynamics".

\section{REFERENCES}

1. Schmauss C, Doherty C, Yaksh TL. The analgesic effects of an intrathecal administered partial opiate agonist, nalbuphine hydrochloride. Eur J Pharmacol 1982;86(1):17.

2. Schmauss C, Doherty C, Yaksh TL. The analgesic effects of an intrathecally administered partial opiate agonist, nalbuphine hydrochloride. Eur J Pharmacol 1983;86:1-7.

3. Schmauss C, Yaksh TL. In vivo studies on spinal opiate receptor systems mediating antinociception. II. Pharmacological profiles suggesting a differential association of mu, delta and kappa receptors with visceral chemical and cutaneous thermal stimuli in the rat. J Pharmacol Exp Ther 1984;228(1):1-12.

4. Jaffe JH, Martin WR. Opioid analgesics and antagonists. $7^{\text {th }}$ ed. In: Gilman AG, Goodman LS, Rall TW, (eds). The pharmacological basis of therapeutics. New York, Mac Millan 1985:505.

5. Morando R, Sinatra RS, Fu ES, et al. Failure of intrathecally administered nalbuphine yo suppress visceral pain in pregnant rats. Anesthesiology 1987;67:A447.

6. Malinow AM, Mokriski BLK, Wakefield ML, et al. Choice of local anesthetic affects post-cesarean epidural fentanyl analgesia. Regional Anesthesia 1988;13(4):141-5.

7. Hughes SC, Wright RG, Murphy D, et al. The effect of $\mathrm{pH}$ adjusting 3\% 2-chloroprocaine on the quality of postcesarean section analgesia with epidural morphine. Anesthesiology 1988;69(3A):A689.

8. Wang JJ, Swei SP, Can KH, et al. Postoperative pain relief with various epidural narcotics: Demerol, butorphanol, nalbuphine and morphine. Ma Tsui Hsueh Tsu Chi 1988;26:15-24.

9. Weksler N, Ovadia L. Preliminary study of epidural nalbuphine in treatment of postoperative pain: a comparison with equipotent dose of epidural morphine. Journal of Anesthesia 1989;3(1):54-7.

10. Ackerman WE, Juneja MM. 2-chloroprocaine decreases the duration of analgesia of epidural fentanyl. Anesth Analg 1989;68:52.

11. Dougherty TB, Baysinger CL, Henenberger JC, et al. Epidural hydromorphone with and without epinephrine for postoperative analgesia after cesarean delivery. Anesth Analg 1989;68(3):318-22.

12. Grice SC, Eisenach JC, Dewan DM. Labor analgesia with epidural bupivacaine plus fentanyl: enhancement with epinephrine and inhibition with 2-chloroprocaine. Anesthesiology 1990;72(4):623-8.

13. Camann WR, Hartigan PM, Gilbertson LI, et al. Chloroprocaine antagonism of epidural opioid analgesia: a receptor specific phenomenon? Anesthesiology 1990;73(5):860-3. 
14. Rawal N, Nuutinen L, Raj PP, et al. Histopathological effects of intrathecal sufentanil, butorphanol and nalbuphine. Pain 1990;42:S130.

15. Baxter AD, Laganiere S, Samson B, et al. A dose-response study of nalbuphine for post-thoracotomy epidural analgesia. Can J Anaesth 1991;38(2):175-82.

16. Rawal N, Nuutinen L, Lovering SL. Behavioral and histopathologic effects following intrathecal administration of butorphanol, sufentanil, and nalbuphine in sheep. Anesthesiology 1991;75(6):1025-34.

17. Cohen SE, Ratner EF, Kreitzman TR, et al. Nalbuphine is better than naloxone for treatment of side effects after epidural morphine. Anesth Analg 1992;75(5):747-52.

18. Paqueron $X$, Galinski M, Boudet $L$, et al. A low dose of nalbuphine, reverses respiratory depression but not analgesia induced by intraspinal morphine. Ann Fr Anesth Reanim. 1997;16(3):294-6.
19. Parker RK, Holtmann B, White PF. Patient-controlled epidural analgesic: interaction between nalbuphine and hydromorphone. Anesth Analg 1997;84(4):757-63.

20. Fournier R, Gessal EV, Macksay M, et al. Onset and offset of intrathecal morphine versus nalbuphine for postoperative pain relief after total hip replacement. Acta Anaesthesiol Scand 2000;44(8):940-5.

21. Fournier R, Gamulin Z, Macksay $M$, et al. Intrathecal morphine versus nalbuphine for postoperative pain relief after total hip replacement. Anesthesiology 1998;89:867.

22. Somrat C, Oranuch K, Ketchada U, et al. Optimal dose of nalbuphine for treatment of intrathecal-morphine induced pruritus after caesarean section. J Obstet Gynaecol Res 1999;25(3):209-13.

23. Charuluxananan $S$, Kyokong 0 , Somboonviboon $W$, et al. Nalbuphine versus propofol for treatment of intrathecal morphine-induced pruritus after cesarean delivery. Anesth Analg 2001;93(1):162-5. 